\title{
Persistent hypertriglyceridemia in statin-treated patients with type 2 diabetes mellitus
}

This article was published in the following Dove Press journal:

Diabetes, Metabolic Syndrome and Obesity:Targets and Therapy

9 January 2013

Number of times this article has been viewed

\author{
Michael Feher ${ }^{1-3}$ \\ Mark Greener ${ }^{4}$ \\ Neil Munro ${ }^{1-3,5}$ \\ 'Beta Cell Diabetes Centre, Chelsea \\ and Westminster Hospital, London, \\ ${ }^{2}$ Diabetes Therapies Evaluation \\ Network, London, ${ }^{3} \mathrm{CSRI}$, Warwick \\ University, Warwick, ${ }^{4}$ ROCK Medical \\ Communications, Richmond, \\ ${ }^{5}$ Department of Health Care \\ Management, University of Surrey, \\ Guildford, Surrey, UK
}

Purpose: This paper reports the results of an audit that assessed the prevalence of residual hypertriglyceridemia and the potential need for intensified management among patients with statin-treated type 2 diabetes mellitus (T2DM) in primary care in the UK.

Patients and methods: A cross-sectional, observational, systematic audit of patients with diagnosed diabetes from 40 primary care practices was undertaken. The audit collected basic demographic information and data on prescriptions issued during the preceding 4 months. T2DM patients were stratified according to the proportion that attained European Society of Cardiology treatment targets.

Results: The audit collected data from 14,652 patients with diagnosed diabetes: $89.5 \%$ ( $n=13,108)$ of the total cohort had T2DM. Of the people with T2DM, 22.2\% (2916) were not currently receiving lipid-lowering therapy. Up to approximately $80 \%$ of these people showed evidence of dyslipidemia. Among the group that received lipid-lowering therapy, 94.7\% (9647) were on statin monotherapy, which was usually simvastatin $(69.5 \%$ of patients receiving statin monotherapy; 6707). The currently available statins were prescribed, with the most common dose being $40 \mathrm{mg}$ simvastatin $(44.2 \%$; 4267). Irrespective of the statin used, around half of the patients receiving statin monotherapy did not attain the European Society of Cardiology treatment targets for triglycerides, low-density lipoprotein, high-density lipoprotein, and total cholesterol.

Conclusion: T2DM patients managed in UK primary care commonly show persistent lipid abnormalities. Clinicians need to optimize compliance with lipid-lowering and other medications. Clinicians also need to consider intensifying statin regimens, prescribing additional lipidmodifying therapies, and specific treatments aimed at triglyceride lowering to improve dyslipidemia control in statin-treated patients with T2DM.

Keywords: triglycerides, lipid-lowering treatment, diabetic dyslipidemia, simvastatin, audit

\section{Introduction}

Patients with diabetes are at increased risk of morbidity and mortality from cardiovascular disease (CVD) compared to normoglycemic controls. ${ }^{1}$ Several additional factors may be associated with this increased risk, including persistent hyperglycemia, untreated hypertension, and dyslipidemia characterized by raised serum triglycerides (TG) and low concentrations of high-density lipoprotein cholesterol (HDL-C). ${ }^{2}$

The reduction in cardiovascular events produced by statins in patients with diabetes is broadly consistent with that in normoglycemic, dyslipidemic controls. In the Collaborative Atorvastatin Diabetes Study (CARDS), a primary prevention study in type 2 diabetes mellitus (T2DM), atorvastatin reduced coronary heart disease events by $36 \%$, stroke by $48 \%$, and mortality by $27 \%{ }^{3}$ In a meta-analysis of secondary
Correspondence: Michael Feher Beta Cell Diabetes Centre, Chelsea and Westminster Hospital, 369 Fulham Road, London, SWIO 9NH, UK

Tel +44208746882I

Fax +442033152732

Email michael.feher@chelwest.nhs.uk 
prevention studies in T2DM, statins reduced cardiovascular events by $28 \%$ and strokes by $32 \% .{ }^{4}$ Despite this efficacy, a considerable residual cardiovascular risk remains among patients receiving statin therapy. ${ }^{2,5}$

Hypertriglyceridemia $(>1.7 \mathrm{mmol} / \mathrm{L})$ alters the composition of atherogenic particles and may make an important pathophysiological contribution to the residual cardiovascular risk. ${ }^{6}$ Indeed, the current European Atherosclerosis Society consensus statement recommends treating hypertriglyceridemia of $\geq 1.7 \mathrm{mmol} / \mathrm{L}$. ${ }^{6}$ Statins, as well as lowering LDL-C, reduce blood triglyceride concentrations by up to $40 \%$. $^{7,8}$

Only a few previous studies have evaluated hypertriglyceridemia in statin-treated patients with T2DM. ${ }^{9,10}$ However, there is little data evaluating these patients in primary care in the UK. Therefore, this audit assessed the prevalence of residual hyperlipidemia and the potential need for additional lipid-lowering therapy in individuals with T2DM treated with statins in primary care in the UK.

\section{Patients and methods}

This cross-sectional, observational study audited all patients with diabetes from the first 40 primary care practices that agreed to participate from an existing panel established by an independent clinical research organization (Quintiles Commercial UK Limited, Bracknell, UK). Quintiles performed the audit in January and February 2011.

Demographic and prescription data were collected. Prescriptions issued were assessed during the preceding 4 months and repeat prescriptions were included. After excluding patients with forms of diabetes other than T2DM, the patients were stratified according to the European Society of Cardiology (ESC) "feasible" treatment targets in patients with diabetes: total cholesterol (TC) of $<4 \mathrm{mmol} / \mathrm{L}, \mathrm{LDL}-\mathrm{C}$ of $<2.0 \mathrm{mmol} / \mathrm{L}, \mathrm{HDL}-\mathrm{C}$ of $>1.0 \mathrm{mmol} / \mathrm{L}$ (male) or HDL-C $>1.2 \mathrm{mmol} / \mathrm{L}$ (female), and fasting TG of $<1.7 \mathrm{mmol} / \mathrm{L} .{ }^{11}$

Due to the relatively small numbers of patients receiving combination therapy or monotherapy with lipid-lowering drugs other than statins, this analysis focused on target attainment among patients taking statin monotherapy. Descriptive statistics were performed using Microsoft Excel 2010 (Microsoft, Redmond, WA). Due to limitations in the demographic data (see "Discussion"), inferential and comparative statistical analyses were not performed.

\section{Results}

\section{Study population}

The audit captured data on 14,652 patients with diagnosed diabetes from 40 practices. On average, each practice contributed 366 patients with diabetes (range 103-737). Of these, $89.5 \%(n=13,108)$ had T2DM (median age: 66 years old, range: $17-106 ; 44.7 \%$ female).

\section{Patients with T2DM who were not currently receiving lipid-lowering therapy}

Approximately one-fifth $(22.2 \% ; 2916)$ of the total T2DM cohort had not received a prescription for lipid-lowering therapy during the 4 months before the audit. Most of these untreated patients showed evidence of dyslipidemia (Table 1). For example, only around one-fifth were within the target values for total cholesterol and LDL-C.

\section{Patients with T2DM who received lipid-lowering therapy}

Of patients with T2DM who received lipid-lowering therapy, $94.7 \%$ (9647) received statin monotherapy, which was usually simvastatin or atorvastatin (Table 2). Approximately half of the patients who received statin monotherapy attained the ESC treatment targets for total cholesterol, LDL-C, HDL-C, or TG (Table 3). Indeed, irrespective of the individual statin used, around half of patients receiving statin monotherapy attained the ESC treatment targets (Table 2). Table 4 summarizes the dose distribution of each statin in T2DM patients taking monotherapy.

\section{Discussion}

This large, cross-sectional, observational, systematic audit showed that, first, dyslipidemia is common among people with T2DM in the UK and, secondly, that lipid concentrations generally and TG in particular remain elevated despite statin monotherapy. Indeed, just over a fifth of T2DM patients were not receiving lipid-lowering therapy, despite up to approximately $80 \%$ of these subjects showing evidence of dyslipidemia (Table 1). Persistent hypertriglyceridemia was

Table I Proportion of patients with type 2 diabetes mellitus who attained the European Society of Cardiology treatment targets while not receiving any lipid-lowering treatment*

\begin{tabular}{lll}
\hline Lipid parameter & $\begin{array}{l}\text { Number, } \\
\mathbf{n} / \mathbf{N}\end{array}$ & $\begin{array}{l}\text { \% of total } \\
\text { population }\end{array}$ \\
\hline $\mathrm{TC}<4 \mathrm{mmol} / \mathrm{L}$ & $599 / 2750$ & 21.2 \\
$\mathrm{LDL}-\mathrm{C}<2.0 \mathrm{mmol} / \mathrm{L}$ & $473 / 2459$ & 19.2 \\
$\mathrm{HDL}-\mathrm{C}>1.0 \mathrm{mmol} / \mathrm{L}$ (male) & $900 / 1458$ & 61.7 \\
$\mathrm{HDL}-\mathrm{C}>1.2 \mathrm{mmol} / \mathrm{L}$ (female) & $727 / 1307$ & 55.6 \\
Fasting TG $<1.7 \mathrm{mmol} / \mathrm{L}$ & $1539 / 2667$ & 57.7 \\
\hline
\end{tabular}

Note: *Any lipid-lowering treatment includes statins, fibrates, nicotinic acids, and polyunsaturated fatty acids either as monotherapy or in combination.

Abbreviations: HDL-C, high-density lipoprotein cholesterol; LDL-C, low-density lipoprotein cholesterol; TC, total cholesterol. 
Table 2 Proportion of patients with type 2 diabetes mellitus who received statin monotherapy and attained the European Society of Cardiology triglycerides (TG) targets while receiving statin monotherapy

\begin{tabular}{lllll}
\hline Statin & $\begin{array}{l}\text { Number of patients } \\
\text { receiving statin } \\
\text { monotherapy } \\
\mathbf{( N = 1 2 , 4 1 9 )}\end{array}$ & $\begin{array}{l}\text { \% of the total number } \\
\text { of patients receiving } \\
\text { statin monotherapy } \\
\text { treated with each statin }\end{array}$ & $\begin{array}{l}\text { Number of patients } \\
\text { treated with statin } \\
\text { monotherapy and } \\
\text { had TG level recorded }\end{array}$ & $\begin{array}{l}\text { \% of patients treated with } \\
\text { statin monotherapy and } \\
\text { had TG level recorded } \\
\text { who attained TG target } \\
(<\mathbf{I . 7} \text { mmol/L) }\end{array}$ \\
\hline Simvastatin & 6707 & 69.5 & 6351 & 56.1 \\
Atorvastatin & 2154 & 22.3 & 2063 & 48.3 \\
Rosuvastatin & 428 & 4.4 & 409 & 42.8 \\
Pravastatin & 316 & 3.3 & 297 & 52.5 \\
Fluvastatin & 42 & 0.4 & 41 & 56.1 \\
\hline
\end{tabular}

common, occurring in half of those on statin monotherapy (Table 2).

This audit is, as far as the authors are aware, the first large study performed solely from the perspective of primary care in the UK that assesses triglyceride concentrations in patients with $\mathrm{T} 2 \mathrm{DM}$ receiving statin monotherapy. The results confirm the findings of the Dyslipidemia International Study (DYSIS), which stratified patients according to the presence or absence of CVD. In patients with diagnosed CVD, 37.5\% did not reach the LDL-C target, 38.3\% were not at the HDL-C target, and $49.1 \%$ did not achieve the triglyceride target. Among patients without CVD, the proportions were $45.0 \%, 30.4 \%$, and $44.8 \%$ respectively. Only around a quarter $(25.2 \%$ and $25.8 \%$ with and without CVD, respectively) achieved all three targets. ${ }^{9}$ In another study, $20.9 \%$ of 182 patients with T2DM taking statins showed hypertriglyceridemia ( $\geq 2.3 \mathrm{mmol} / \mathrm{L})$. The prevalence of hypertriglyceridemia was lower in patients with LDL-C $<2.5 \mathrm{mmol} / \mathrm{L}(13.7 \%)$, LDL-C $<2.0 \mathrm{mmol} / \mathrm{L}$ $(8.8 \%)$, and HDL-C $\leq 0.9 \mathrm{mmol} / \mathrm{L}(6.0 \%) .{ }^{10}$

In the present study, simvastatin $40 \mathrm{mg}$ was the most frequently prescribed statin dose. However, $35.2 \%$ of simvastatin users took $20 \mathrm{mg}$ or less, $24.7 \%$ of atorvastatin users took $10 \mathrm{mg}, 28.2 \%$ of pravastatin users took $20 \mathrm{mg}$, and

Table 3 Proportion of patients with type 2 diabetes mellitus who attained the European Society of Cardiology treatment targets while receiving statin monotherapy

\begin{tabular}{lll}
\hline Lipid parameter & $\begin{array}{l}\text { Number, } \\
\text { n/N }\end{array}$ & $\begin{array}{l}\text { \% of those } \\
\text { using statin }\end{array}$ \\
\hline $\mathrm{TC}<4 \mathrm{mmol} / \mathrm{L}$ & $4284 / 9052$ & 47.3 \\
$\mathrm{LDL}-\mathrm{C}<2.0 \mathrm{mmol} / \mathrm{L}$ & $3445 / 820 \mathrm{I}$ & 42.0 \\
$\mathrm{HDL}-\mathrm{C}>1.0 \mathrm{mmol} / \mathrm{L}$ (male) & $3096 / 5307$ & 58.3 \\
$\mathrm{HDL}-\mathrm{C}>1.2 \mathrm{mmol} / \mathrm{L}$ (female) & $2252 / 4 \mathrm{I32}$ & 54.5 \\
Fasting TG $<\mathrm{I} .7 \mathrm{mmol} / \mathrm{L}$ & $49 / 6 / 916 \mathrm{I}$ & 53.7 \\
\hline
\end{tabular}

Abbreviations: HDL-C, high-density lipoprotein cholesterol; LDL-C, low-density lipoprotein cholesterol; TC, total cholesterol; TG, triglycerides.
$72.2 \%$ of rosuvastatin users took $10 \mathrm{mg}$ or less (Table 4 ). This pattern of statin use is similar to that observed in other studies. For example, simvastatin was the most widely prescribed statin in the DYSIS, in which the most common regimen was $20-40 \mathrm{mg}$ /day simvastatin equivalent. ${ }^{9}$ In a Swedish study, $76 \%$ of simvastatin users took $20 \mathrm{mg}$ or less, $48 \%$ of atorvastatin users took $10 \mathrm{mg}, 55 \%$ of pravastatin users took $20 \mathrm{mg}$, and $76 \%$ of rosuvastatin users took $10 \mathrm{mg}$ or less. ${ }^{12}$ The cross-sectional nature of the present audit and lack of clinical detail about each patient precluded an examination of any dose-response relationship with statins or ascertaining of whether the low dose was clinically justified (eg, due to concurrent conditions or adverse events). Nevertheless, the data and previous studies suggest that a considerable proportion of patients receives low doses of statin and, as

Table 4 Proportion of patients with type 2 diabetes mellitus who received statin monotherapy, stratified by dose

\begin{tabular}{llll}
\hline Statin & $\begin{array}{l}\text { Dose, } \\
\mathbf{m g}\end{array}$ & $\begin{array}{l}\text { Number of patients } \\
\text { receiving } \\
\text { each dose }\end{array}$ & $\begin{array}{l}\text { \% of patients } \\
\text { receiving the } \\
\text { dose of each statin }\end{array}$ \\
\hline Atorvastatin & 10 & 532 & 24.7 \\
& 20 & 709 & 32.9 \\
& 40 & 746 & 34.6 \\
Fluvastatin & 20 & 167 & 7.8 \\
& 40 & 25 & 31.0 \\
& 80 & 4 & 59.5 \\
Pravastatin & 10 & 72 & 9.5 \\
& 20 & 89 & 22.8 \\
& 40 & 155 & 28.2 \\
Rosuvastatin & 5 & 57 & 49.1 \\
& 10 & 252 & 13.3 \\
& 20 & 104 & 58.9 \\
& 40 & 15 & 24.3 \\
Simvastatin & 10 & 423 & 3.5 \\
& 20 & $1935 *$ & 6.3 \\
& 40 & 4267 & 28.9 \\
& 80 & 82 & 63.6 \\
\hline
\end{tabular}

Note: *Includes one patient taking $20 \mathrm{mg} / \mathrm{mL}$ liquid suspension. 
a result, may be undertreated. As such, there may be scope to intensify statin regimens in many T2DM patients with dyslipidemia who are managed in primary care.

The major limitation of this study is the absence of any information regarding the possible contribution made by potential confounders (such as coexisting obesity, dietary issues, secondary hypertriglyceridemia, impaired renal and hepatic function, and suboptimal glycemic control) to the suboptimal management of triglyceride levels. This reflects the nature of data derived from a cross-sectional audit. For example, more potent statins (atorvastatin, rosuvastatin, and pitavastatin) produce a "robust lowering" of TG, especially at high doses and in patients with hypertriglyceridemia. ${ }^{13}$ However, in this audit, a numerically smaller proportion of patients receiving more potent statins (atorvastatin and rosuvastatin) attained the treatment targets than those taking simvastatin.

Similarly, the nature of the audit meant that we could not ascertain whether the subjects had relatively treatmentresistant dyslipidemia or were in the titration phase, or whether there were any differences between patients receiving statins and the group that did not receive any lipidlowering medication. For example, some patients might have stopped statins after experiencing unacceptable adverse events. Moreover, we could not correlate $\mathrm{HbA}_{1 \mathrm{c}}$ levels or compliance with hypoglycemic medication with use of statins or triglyceride levels. However, the present study is based on data from a large number of patients and, therefore, probably accurately represents the proportions of people with T2DM who attain lipid targets currently in UK primary care. As such, the audit underscores the need to ascertain the reasons why patients failed to attain the treatment targets and to consider intensified intervention.

The ESC guidelines specify treatment targets based on fasting triglyceride levels. However, the audit was unable to ascertain whether triglyceride levels were measured in the fed or fasting state. Fasting levels may reduce uncertainties associated with differences in the time of postprandial phlebotomy. However, postprandial lipids, partially hydrolyzed chylomicron, and very-LDL remnants apparently accelerate atherogenesis by exacerbating endothelial dysfunction, augmenting numbers of atherogenic small LDL particles, and promoting thrombosis and inflammation. Arguably, therefore, postprandial TG more accurately predict vascular risk than fasting levels. ${ }^{14}$ As a result, both fed and fasting hypertriglyceridemia are associated with increased CVD risk. The high prevalence of hypertriglyceridemia identified in this audit suggests that TG are often undertreated.
Numerous secondary causes - including hypothyroidism, renal impairment, hepatic inflammation, and poor glycemic control - may increase TG and should be diagnosed and managed. ${ }^{15}$ However, in this study, the number of patients who had secondary hypertriglyceridemia and the extent to which concurrent conditions influenced the likelihood of attaining the treatment targets could not be assessed.

Despite these caveats, the results of the present study have implications for management. For example, clinicians should continue to emphasize that all patients should follow dietary advice and exercise regularly to improve glycemic control and lipid profiles, as well as implementing interventions to optimize compliance with lifestyle changes, and lipid-lowering and other medications. The audit showed that relatively few patients with T2DM received statins in combination with ezetimibe, fibrate, omega 3 polyunsaturated fatty acids, or nicotinic acid. As many patients show dyslipidemic profiles that are associated with an increased risk of CVD despite statin treatment, clinicians need to consider intensifying statin regimens, offering additional lipid-modifying therapies generally, or regimens specifically aimed at lowering TG levels (such as pharmaceutical grade, highly purified omega 3-acid ethyl esters), particularly to improve the management of diabetic dyslipidemia.

\section{Conclusion}

T2DM patients managed in UK primary care commonly show persistent lipid abnormalities. In this study, over a fifth of T2DM patients were found to be not receiving lipidlowering therapy. Half of those on statin monotherapy had persistent hypertriglyceridemia. Clinicians need to implement interventions to optimize compliance with lipid-lowering and other medications. Clinicians also need to consider intensifying statin regimens, prescribing additional lipid-modifying therapies, and specific treatments aimed at triglyceride lowering to improve dyslipidemia control in statin-treated patients with T2DM.

\section{Acknowledgment}

The authors would like to acknowledge the editorial and analytic support of ROCK Medical Communications.

\section{Disclosure}

The authors analysed and interpreted the data and wrote the manuscript. Abbott Healthcare Products Limited conceived of and funded the original audit and the preparation of the manuscript. Abbott did not actively contribute to the content 
but reviewed the final piece for scientific accuracy. Dr Feher and Dr Munro have received honoraria for research and consultancy from pharmaceutical firms marketing lipid lowering drugs - Abbott, Pfizer and MSD. Mark Greener has no other conflicts of interest in this work.

\section{References}

1. Haffner SM, Lehto S, Rönnemaa T, Pyörälä K, Laakso M. Mortality from coronary heart disease in subjects with type 2 diabetes and in nondiabetic subjects with and without prior myocardial infarction. N Engl J Med. 1998;339(4):229-234.

2. Heart Protection Study Collaborative Group. MRC/BHF Heart Protection Study of cholesterol lowering with simvastatin in 20,536 high-risk individuals: a randomised placebo-controlled trial. Lancet. 2002;360(9326):7-22.

3. Colhoun HM, Betteridge DJ, Durrington PN, et al; CARDS investigators. Primary prevention of cardiovascular disease with atorvastatin in type 2 diabetes in the Collaborative Atorvastatin Diabetes Study (CARDS): multicentre randomised placebo-controlled trial. Lancet. 2004;364(9435):685-696.

4. Keech A, Colquhoun D, Best J, et al; LIPID Study Group. Secondary prevention of cardiovascular events with long-term pravastatin in patients with diabetes or impaired fasting glucose: results from the LIPID trial. Diabetes Care. 2003;26(10):2713-2721.

5. Krobot KJ, Wagner A, Siebert U. Risk factor levels, risk factor combinations, and residual coronary risk: population-based estimates for secondary prevention patients using statins. Eur J Prev Cardiol. 2012;19(1):109-117.

6. Chapman MJ, Ginsberg HN, Amarenco P, et al; European Atherosclerosis Society Consensus Panel. Triglyceride-rich lipoproteins and highdensity lipoprotein cholesterol in patients at high risk of cardiovascular disease: evidence and guidance for management. European Heart J. 2011;32(11):1345-1361.
7. Solano MP, Goldberg RB. Lipid management in type 2 diabetes. Clin Diabetes. 2006;24(1):27-32.

8. Oh RC, Lanier JB. Management of hypertriglyceridemia. Am Fam Physician. 2007;75(9):1365-1371.

9. Leiter LA, Lundman P, da Silva PM, Drexel H, Jünger C, Gitt AK; DYSIS investigators. Persistent lipid abnormalities in statin-treated patients with diabetes mellitus in Europe and Canada: results of the Dyslipidaemia International Study. Diabet Med. 2011;28(11):1343-1351.

10. Hamilton SJ, Chew GT, Davis TM, Stuckey BG, Watts GF. Hypertriglyceridaemia in statin-treated type 2 diabetic patients. Practical Diabetes International. 2011;28(6):257-260.

11. Graham I, Atar D, Borch-Johnsen K, et al; European Society of Cardiology (ESC) Committee for Practice Guidelines (CPG). European guidelines on cardiovascular disease prevention in clinical practice: executive summary: Fourth Joint Task Force of the European Society of Cardiology and Other Societies on Cardiovascular Disease Prevention in Clinical Practice (Constituted by representatives of nine societies and by invited experts). European Heart J. 2007;28(19):2375-2414.

12. Eliasson B, Svensson AM, Miftaraj M, et al. Clinical use and effectiveness of lipid lowering therapies in diabetes mellitus - an observational study from the Swedish National Diabetes Register. PLoS One. 2011;6(4):e18744.

13. European Association for Cardiovascular Prevention and Rehabilitation, Reiner Z, Catapano AL, et al; ESC Committee for Practice Guidelines (CPG) 2008-2010 and 2010-2012 Committees. ESC/EAS Guidelines for the management of dyslipidaemias: the Task Force for the management of dyslipidaemias of the European Society of Cardiology (ESC) and the European Atherosclerosis Society (EAS). European Heart $J$. 2011;32(14):1769-1818.

14. Kannel WB, Vasan RS. Triglycerides as vascular risk factors: new epidemiologic insights. Curr Opin Cardiol. 2009;24(4):345-350.

15. Schaefer EW, Leung A, Kravarusic J, Stone NJ. Management of severe hypertriglyceridemia in the hospital: a review. J Hosp Med. 2012; 7(5):431-438.

\section{Publish your work in this journal}

Diabetes, Metabolic Syndrome and Obesity: Targets and Therapy is an international, peer-reviewed open-access journal committed to the rapid publication of the latest laboratory and clinical findings in the fields of diabetes, metabolic syndrome and obesity research Original research, review, case reports, hypothesis formation, expert opinion and commentaries are all considered for publication. The manuscript management system is completely online and includes a very quick and fair peer-review system, which is all easy to use. Visit http://www.dovepress.com/testimonials.php to read real quotes from published authors. 